\title{
ANDE-1 \\ An ASME Nondestructive Examination and Quality Control Qualification and Certification National Standard
}

\author{
Michael L. Turnbow \\ Independent Consultant \\ Chairman, ANDE Committee
}

\begin{abstract}
The American Society for Mechanical Engineers (ASME) is developing and implementing a Nondestructive Examination (NDE) and Quality Control (QC) personnel qualification and certification program (ANDE). In keeping with ASME development of codes and standards the NDE program will be assembled by industry experts and administered centrally by ASME. A new ASME standard recognized by the American National Standards Institute (ANSI) is being developed as the core of the program and will be based upon industry best practices. The total program is a significant paradigm change from the traditional employer based and other central qualification and certification programs, the new standard will include features such as the Systematic Approach to Training, Job Task Analysis and Qualification Cards to direct the development of training and experience. The program was designed to improve the skill level and consistency amongst NDE practitioners and will use the performance-based approach including psychometric practices in the development of both written and practical demonstration examinations. This paper will primarily focus on the development of the standard and its salient features.
\end{abstract}

\section{INTRODUCTION}

This paper provides a rationale for the development of a new ASME standard addressing a Central Qualification and Certification Program for Nondestructive Examination (NDE) and Quality Control (QC) Personnel (ANDE). Performance-based concepts are being used to serve as the program core and will address the needs of nuclear and many other industries that require reliable NDE and QC to be performed using qualified and certified personnel. The use of a performance-based approach with a Systematic Approach to Training (SAT) process along with developing Job Task Analyses (JTAs) for NDE and QC personnel makes ANDE unique, and supports the goal to enhance personnel capabilities to perform these activities. As a result of nuclear power plant operator performance during the Three Mile Island incident in 1979, the Institute of Nuclear Power Plant Operations (INPO) implemented the SAT process in the early 1980 's. Since then operators and other power plant workers have realized significant performance improvements. However, NDE and QC were not included. It is expected that with the implementation of ANDE the performance issues addressed in this paper will be improved and that a larger pool of personnel will become available to support any Industry or Specific Industry Sector that either requires or chooses to use this standard.

Nondestructive Examination and Quality Control Inspection plays a critical role in ensuring nuclear power plants are safe and ready for continued operation and are equally important to the economic success and safe operation of complex engineering systems in other industries. Starting with the manufacturing of materials, fabrication, construction, pre-service inspection and in-service inspection, $\mathrm{NDE}$ and QC are applied every step along the way to make sure final components are free of defects and fit for service. The inspections support a defense in depth that is systematically required through the ASME Code and Federal Regulations. The U. S. Nuclear Regulatory Commission (NRC) often refers to 
NDE and inspection as the "final safety net". The reason being that NDE is often the last evaluation of materials to assure components are free of defects before being placed in service. The application of NDE and QC in nuclear power plants includes critical safety significant high temperature and pressure retaining components such as the reactor pressure vessel, associated piping and many other component applications essential to safe operations. The reliability of NDE and inspection to reliably detect and accurately size flaws has a tremendous potential to not only affect plant operations, but also more importantly affect the safety of plant personnel and the general public.

Data over the past 30 years provides a basis to re-evaluate the effectiveness of the processes currently used to qualify and certify personnel. The data shows NDE continues to demonstrate considerable inconsistent performance in both round robin studies and as experienced by industry in the failure to detect or properly identify material degradation conditions. In many cases, flaws have been missed resulting in component failure in operating plants.

Electric Power Research Institute (EPRI) report 1016969 [1] summarizes round robin studies collected over a 30 year period and concludes, "The pass rate obtained by experienced (NDE) certified personnel is rarely $50 \%$ on first attempt at a demonstration test that simulates the examination conducted in the field." Another EPRI study (report 1013546) [2] addressed the specific NDE performance demonstration test for Intergranular Stress Corrosion Cracking (IGSCC) administered at the EPRI NDE Center. The examination was assembled as an industry and NRC response to NDE missing IGSCC flaws at Nine Mile Point in 1982 resulting in pipe failure. The study shows the initial pass rates as low as $18 \%$ and those that did pass were re-examined after 3 years with a pass rate of only $50 \%$. These were personnel qualified and certified in accordance with the employer's written practice, and was the traditional approach at that time. The qualification and certification process used then has basically gone unchanged and is still used today.

The data from round robin studies and pass rates from the IGSCC performance demonstration initial and requalification examinations lead to the conclusion that similar flaw detection performance would be expected on applications in actual nuclear power plants. It should therefore not be surprising to find that nearly all material degradation conditions have gone essentially undetected by NDE throughout the history of U.S. commercial nuclear power and ultimately lead to component leakage and/or failure. The following were all missed by NDE and resulted in the material failure during nuclear operation:

- Intergranular stress corrosion cracking in BWR stainless steel welds in early 1980s

- Thermal fatigue cracking in steam generator feed water nozzles in late 1980's and early 1990's

- Primary water stress corrosion cracking in steam generator tubing in late 1980's and early1990's

- Stress corrosion cracking in alloy 600/82/182 materials starting in early 2000 with events continuing to-date

Steven R. Doctor, Ph.D., Laboratory Fellow, Applied Physics/National Security Directorate and recently retired from the Pacific Northwest National Laboratory made the following statement in a paper presented at the PVP 2008 conference in Chicago, “.... detection of these degradation processes did not occur by ISI (in-service inspection by NDE) but were first found by water on the floor."

Numerous other operating experiences (OE) have occurred as a result of NDE performance issues. For example, since early 2000 more than twenty nuclear plants have been affected where NDE either missed or miscalled flaws. In addition flaws were miscalled during an NRC research project on a St. Lucie pressurizer in the spring of 2008 and almost caused an 8-unit shut down by the Nuclear Regulatory 
Commission (See NEI Overview Weekly Report March 3, 2008). Another OE was reported during spring 2012 at Dominion's North Anna Plant where UT inspectors missed 5 large axial flaws on a steam generator hot leg dissimilar weld. NDE failures and other performance issues since the introduction of IGSCC in 1982 have collectively cost the industry millions of dollars and degraded regulatory confidence.

On January 12, 2010, the NRC wrote a letter to ASME expressing concerns about NDE probability of detection and ASNT grading practices (See NRC ADAMS Public Web Site Accession Number ML100140091) [3]. In the summer of 2010 industry and ASME established an initiative to address the NDE performance issues. An ASME NDE (ANDE) committee was formed to develop a training, qualification and certification program including written examinations and performance based practical tests. In the spring of 2011 a request to fund the project was distributed to the owners of all 104 nuclear units. Initial funding from utilities, the NRC and U.S. Department of Labor (DOL) grant totaling approximately $\$ 2.2$ million has been adequately sufficient for ANDE program development to date.

A review of the current employer based personnel qualification and certification (PQ\&C) process should provide insights and understanding of the weaknesses leading to the poor NDE performance issues. Every employer (manufacturer, vendor or utility) has their own PQ\&C self-certification program including non-standardized training, experience, written and practical examinations. Upon acceptance of these qualifications, which varies across the industry, each employer issues a non-portable certification (i.e., each time an employee changes jobs this costly, redundant and inefficient process may start all over again).

The following summarizes the employer-based process currently used by the US nuclear industry:

1) Provides limited specific criteria resulting in broad interpretations and variations.

2) Training-minimum hours only required based on general industry approach, no standard for training development, no industry evaluation for assessing effectiveness of results and performance, no accreditation.

3) Experience-time based only, no specific criteria provided or required, no industry evaluation for assessing effectiveness of results and performance.

4) Written Examinations-only minimum number of questions required, no standard for quality, no criteria provided for development, and psychometric practices are not followed. Questions are actually available for public purchase from ASNT. Some employers still choose to use these questions even though available to the public/workforce.

5) Practical-costly with limited sample sets, typically does not address many conditions expected in the field.

6) No Job Task Analysis (JTA) to define task capabilities, no standard level of difficulty, no way to evaluate effectiveness and quality of either written or practical examination.

7) No effective way to incorporate operating experience into employer based decentralized PQ\&C process.

8) INPO guidelines are not followed. No INPO or other industry independent evaluation of each employers program for effectiveness, i.e., NDE and QC PQ\&C has no oversight to drive improved performance. 
With the introduction of INPO resulting from the Three Mile Island event, much has changed concerning the training and qualification of nuclear power plant workers. The SAT process evolved with detailed training development criteria and continuing industry evaluation for performance effectiveness.

The introduction of INPO has resulted in nuclear power operations continuously improving over the years. The non-standard employer based NDE PQ\&C process has seen little change since introduced over 40 years ago and has never been brought into alignment with INPO Guidelines - SAT process. Each employer is free to interpret the ASNT SNT-TC-1A and CP-189 training outlines and determine independently the depth of training to be provided. Experience requirements are time based only with no other guidelines provided leaving each employer free to determine content and quality. Unlike INPO assessments to determine effectiveness of training of other nuclear power plant workers, there is no independent evaluation that an acceptable standard level of performance is achieved in NDE or that OE has been properly addressed.

Because outages are short in duration and only individuals that are employer certified can perform inspections, and since few flaws are found in operating plants, entry-level personnel have little opportunity to gain experience in evaluating real flaws. Consequently suppliers of NDE personnel must rely on mock-ups. Mockups are very costly and impractical for each employer to obtain representing all possible field conditions. With no formal independent evaluation of this process the employer documents experience time only and when complete proceeds to certify individuals that may or may not be proficient.

In addition to PDI pass rates, round robin studies and nuclear industry OE, the following EPRI studies further confirm weaknesses in the training and experience provisions of the existing employer based selfcertification process. EPRI report 1016969 [1] concludes, “.... exposure to training and job experience (in accordance with the current employer based process) does not necessarily lead to job proficiency. For example, research involving 32 candidates (two groups) for qualification in the EPRI NDE Center PDI program revealed no positive relationship at all between the number of years of NDE ultrasonic, or piping examination experience and performance on ultrasonic examination demonstration test. Results such as these are not puzzling if one recognizes that unstructured training and job experience may or may not include the key factors that are essential for learning."

These NDE performance issues do not reside in the nuclear industry alone. In 2001 the American Petroleum Institute reported an NDE pass rate of $30 \%$ on initial performance demonstration tests. A global petrochemical company reported in 2009 that of 313 inspectors examined over 3 years in various countries had a $30 \%$ pass rate at first attempt for flaw detection and $20 \%$ for flaw sizing. NDE performance in non-nuclear industries and specific industry sectors is extremely relevant since workers may migrate from industry to industry to maintain employment.

With these issues facing the existing work force and with the existing work force retiring at a steady rate, new entry level personnel are destined to repeat these same performance issues if the weaknesses in the existing PQ\&C process are not addressed.

As industry evolved over the years, the NDE community quickly embraced the latitude provided by the employer based NDE PQ\&C process. At first glance the concept seems perfect where each industry and employer addresses their specific needs. But in practice, as the data and OE shows, inconsistencies in the quality of training/experience/evaluation affected by pressures from manpower supply and demand, and cost and schedule all have an impact on how each individual employer deals with PQ\&C. Since there are no standards or formal evaluation process for effectiveness, the customer or end user has responsibility to "police" the NDE provider. This oversight varies broadly from "some" to "none" based on the 
customer/end user in-house knowledge of NDE. If an individual has the documentation required by the employer based process and certified by an employer, they are assumed qualified and expected to perform. Based on the original concept, the employer is responsible to assure NDE personnel are qualified for specific applications. This may or may not be achieved due to the lack of standards and standard evaluation, i.e., the cost of practice mock-ups for numerous plant or industry specific applications may be cost prohibitive for individual suppliers causing lack of consistency and wide ranging variations in implementing the employer based process.

The existing employer based PQ\&C process was introduced in 1968 in the American Society for Nondestructive Testing's (ASNT) recommended practice SNT-TC-1A. The document was later upgraded to an ANSI National Standard - ASNT/ CP-189 in 1991 with basically the "shoulds" changed to "shalls". However both documents were designed for general use with the employer ultimately responsible to address their specific needs. These ASNT documents have been referenced in codes and standards since the early 70's. Unfortunately the generality of the documents, lack of standards for specific industries and no formal independent evaluation for implementation and quantifying effectiveness has contributed to the NDE performance issues.

The weaknesses first surfaced in 1982 when an NDE inspection missed IGSCC at Nine Mile Point, resulting in pressure boundary pipe failure. In fact, even with the knowledge of where the cracks were located, based on observing water leaks in the piping, NDE personnel could not reliably detect the flaws. The NRC and nuclear industry responded with a formal training and performance-testing program centrally administered at the EPRI NDE Center in Charlotte, NC. As previously mentioned, the initial pass rate for detecting IGSCC in components removed from an actual plant was only $18 \%$. These were seasoned employer qualified and certified examiners to the latest ASNT criteria. During this same time the NRC, PNNL and EPRI conducted several round robin studies concluding there were significant performance issues with NDE.

Shortly after the IGSCC failure at Nine Mile Point and upon review of round robin studies conducted in the 1980s, ASME charged Section XI to address the NDE performance issues. In 1989 "ASME Section XI, Appendix VIII "Performance Demonstration for Ultrasonic Examination Systems" was published in the code.

A committee of utility members was established and by the mid 90's Appendix VIII was implemented as the Performance Demonstration Initiative (PDI) and at an original cost to the industry of over \$10 million. Initial first attempt pass rates of existing industry experienced qualified and certified personnel were around $35 \%$. The pass rate eventually rose to approximately $50 \%$ where it hovers to this day (see EPRI PDI Pass Rates at NRC ADAMS Public Web Site [4]:

\section{http://adamswebsearch2.nrc.gov/webSearch2/main.jsp?AccessionNumber='ML12342A249)}

Again, PDI pass rates are just another indicator of the weaknesses in the employer-based process. The industry has subsequently spent millions to develop a "screening" process (PDI) only to find that pass rates are from $18 \%$ to $50 \%$ for a workforce that is supposed to already be qualified and certified. It is estimated that the total cost for PDI (test blocks, guided practice, fees for initial test and multiple retests, travel and per diem) is over $\$ 150$ million to date.

Also as a result of multiple studies and OE, the ASME Code, Section XI, has gradually added 3 pages of additional NDE PQ\&C requirements including three appendices (VI, VII, and VIII). It was believed that the original ASNT PQ\&C employer based process along with the additional Code requirements including PDI would address the NDE performance issues. Unfortunately data and OE to date has shown that PDI is only a "screening tool" and cannot replace appropriate training and experience. PDI has proven you 
cannot test people into being proficient and that there is no substitute for appropriate training and experience in developing the required knowledge and skills.

With the lack of standard evaluation allowing varying levels of skills and knowledge, and with pass rates on centralized performance demonstration tests rarely better than $50 \%$, it should not be surprising that the industry continues to experience NDE issues in operating nuclear power plants.

In summary, the current employer based NDE and QC PQ\&C process lacks the essential elements found in the SAT approach that would result in a level of performance expected by the nuclear power industry. Since the introduction of INPO, the resulting guidelines, best practices and formal evaluation for effectiveness have been successfully applied to other nuclear power plant workers but not to NDE and QC personnel.

There is now sufficient data and $\mathrm{OE}$ indicating that without addressing the root cause (training, experience and evaluation) the current adverse trend will continue. The ANDE program will address these issues and institutionalize a consistent standardized approach for an improved NDE PQ\&C process. Implementation of ANDE will elevate the NDE and QC profession with a transportable certification attractive to entry-level personnel resulting in a much-needed increase in the workforce with expected performance improvements.

The ANDE program is comprehensive in that the goal is to address training, experience, examination, certification and independent evaluation. The program is fully engaged in using appropriate INPO guidelines and best practices including the Systematic Approach to Training (SAT). The INPO guidelines that include the SAT process are available to utility members only. However a description of the SAT process can be found on numerous web sites by using almost any search engine. [6]

The following is the SAT 5-step process:

1. Analysis of a need, task, and job

2. Learning developed from analysis

3. Training designed/developed

4. Evaluation of trainee learning

5. Evaluation of training program

Training materials, experience requirements and examinations will be developed from job task analyses and bodies of knowledge prepared by industry subject matter experts. Separation and independence will be maintained during development of training materials and examinations to assure program integrity. Web-based examinations will be secured and ASME as a 3rd party will control administration. Online training and simulation may be employed and will reduce costs while making it possible to greatly improve individual skills. Simulationns will be an important tool to provide extensive experience applicable to industry specific applications that are otherwise cost prohibitive today. Performance indicators and $\mathrm{OE}$ will be feed back into the training materials and examinations in real time. And finally, self assessments by industry experts including industry audits will provide data for continuous improvement and assure the program meets expectations for effectiveness and performance. Program implementation will receive oversight from a steering committee made up of industry executives and the NRC. 
The status of the ANDE-1 standard and program development is as follows:

- On April 22, 2015 the American National Standards Institute (ANSI) approved "ANDE-1" as an ASME standard for the central certification of NDE/QC personnel. The standard includes requirements for education, training, experience and assessment utilizing INPO guidelines and best practices.

- A special industry task group has designed practical demonstration test pieces. Pacific Northwest National Laboratory (PNNL) assisted in determining the appropriate number of test pieces and flaws that would allow the measurement of Probability of Detection (POD).

- Written UT examination questions have been developed in accordance with Psychometric Practices and are being reviewed by the ANDE Subcommittee on Testing.

- The ANDE Committee has approved the UT and QC Mechanical/Common JTA's. Other NDE/QC JTA's are near completion and ready for ANDE Committee approval.

- The UT Qualification Card is in subcommittee for review/approval, other NDE/QC methods are in development.

- The Body of Knowledge (BOK) with classroom and on-line training is scheduled to be complete by the end of 2015 .

\section{REFERENCES}

1. Nondestructive Evaluation: A Review of NDE Performance Demonstrations - NDE Round Robin Report. EPRI, Palo Alto, CA: 2008. 1016969. (Note: this report is publicly available at (www.epri.com/search/Pages/results.aspx?k=1016969)

2. NDE Performance Demonstration Test for Intergranular Stress Corrosion Cracking. EPRI, Palo Alto, CA: 2005. Report 1013546

3. NRC Letter to ASME. January 12, 2010. NRC ADAMS public wed site, Accession Number ML100140091

4. http://adamswebsearch2.nrc.gov/webSearch2/main.jsp?AccessionNumber='ML12342A249

5. U.S. Department of Energy (DOE). Training Program Handbook: A Systematic Approach to Training (SAT) example. Designation: DOE-HDBK-1078-94. web site:

http://energy.gov/search/site/hdbk-1078-94 